\title{
Synthesis by Click Reactions and Antiplasmodial Activity of Lupeol 1,2,3-Triazole Derivatives
}

\author{
Tatiane F. Borgati, ${ }^{*}, a$ Guilherme R. Pereira ${ }^{b}$ Geraldo C. Brandão, ${ }^{c}$ \\ Juliana O. Santos, ${ }^{a}$ Dayane Aparecida M. Fernandes, ${ }^{a}$ Renata C. de Paula, ${ }^{d}$ \\ Maria Fernanda A. do Nascimento, ${ }^{a}$ Luciana F. Soares, ${ }^{a}$ Júlio César D. Lopes, ${ }^{e}$ \\ José D. de Souza Filho ${ }^{e}$ and Alaíde B. de Oliveira*,a \\ ${ }^{a}$ Departamento de Produtos Farmacêuticos, Faculdade de Farmácia, UFMG, \\ Av. Antônio Carlos, 6627, Campus Pampulha, 31270-901 Belo Horizonte-MG, Brazil \\ ${ }^{b}$ Pontifícia Universidade Católica de Minas Gerais, ICEI, Av. Dom José Gaspar, 500, \\ Prédio 34 Coração Eucarístico, 30535-901 Belo Horizonte-MG, Brazil \\ ${ }^{c}$ Faculdade de Farmácia, UFOP, Rua Costa Sena, 171, 35400-000 Ouro Preto-MG, Brazil

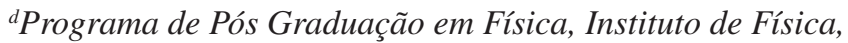 \\ Universidade Federal de Uberlândia (PPFIS-UFU), Av. João Naves de Ávila, 2121, \\ Campus Santa Mônica, 38400-902 Uberlândia-MG, Brazil \\ eDepartamento de Química, Instituto de Ciências Exatas, UFMG, \\ Av. Antônio Carlos, 6627, Campus Pampulha, 31270-901 Belo Horizonte-MG, Brazil
}

Lupeol, a triterpene frequently found in Asteraceae plant species, showed moderate to low activity in different strains of Plasmodium falciparum, the most virulent malaria etiological agents. In this work, lupeol was isolated from Parahancornia fasciculata, a plant that is used to treat malaria in the Amazonia region. In the search of more activity lupeol derivatives, five new 1,2,3-triazole hybrid molecules were synthetized by copper-catalyzed azide-alkyne cycloaddition. The antiplasmodial activity of the semi-synthetic compounds were evaluated by the lactate dehydrogenase assay; the lupeol propargyl ether was the only one to disclosing increased activity (half maximal inhibitory concentration- $\mathrm{IC}_{50}-62.0 \pm 1.92 \mu \mathrm{mol} \mathrm{L} \mathrm{L}^{-1}$ ) in relation to lupeol $\left(\mathrm{IC}_{50} 117.00 \mu \mathrm{mol} \mathrm{L}-1\right)$. Therefore, this work revealed a new class of interesting lupeol derivatives that can be obtained by linking electron donors to the hydroxy group at C-3.

Keywords: lupeol, terpenoids, 1,2,3-triazole, click chemistry, antiplasmodial activity

\section{Introduction}

Malaria, an infectious disease caused by protozoa Plasmodium species and transmitted by Anopheles mosquitoes, is still a serious public health problem in many tropical countries. ${ }^{1}$ According to the World Health Organization (WHO), approximately 214 million cases of malaria occurred globally in $2015 .^{2}$ Most of the cases (88\%) and deaths (90\%) occurred in Africa Region. ${ }^{2}$ In the Americas, Brazil is the country with the highest number of malaria cases. ${ }^{3}$

Plants are still used in the endemic countries as

\footnotetext{
*e-mail: tatianefborgati@yahoo.com.br
}

remedies to treat a range of diseases, including malaria ${ }^{3}$ and afforded important antimalarial drugs, such as quinine (1), an alkaloid that was isolated in 1820 from barks of Peruvian Cinchona species (Rubiaceae) and was widely used until after the Second World War. Quinine was a template for the synthesis of chloroquine (2), in 1940, a quinoline that was widely used in malaria therapeutics ${ }^{4}$ resulting in Plasmodium falciparum resistance, in the 1960s. New antimalarial drugs have been developed such as primaquine (3), mefloquine (4), lumefantrine (5) and amodiaquine (6) (Figure 1). ${ }^{1,4}$

Artemisinin (7), an antimalarial sesquiterpene lactone containing an endoperoxide bridge, was isolated in China from Artemisia annua L., and its semi-synthetic 
<smiles>C=CC1CN2CCC1CC2[C@H](O)c1ccnc2ccc(OC)cc12</smiles>

(1)<smiles>O[C@H](c1cc(C(F)(F)F)nc2c(C(F)(F)F)cccc12)C1CCCCN1</smiles>

(4)<smiles>CCN(CC)CCCC(C)Nc1ccnc2cc(Cl)ccc12</smiles>

(2)<smiles>COc1cc(NC(C)CCCN)c2ncccc2c1</smiles>

(3)<smiles>CCN(CC)Cc1cc(Nc2ccnc3cc(Cl)ccc23)ccc1O</smiles>

(6)

Figure 1. Chemical structures of antimalarials: quinine (1), chloroquine (2), primaquine (3), mefloquine (4), lumefantrine (5) and amodiaquine (6).

derivatives, artesunate $(\mathbf{8})$, artemether $(\mathbf{9})$, arteether (10) and dihydroartemisinin (11), are also used in malaria chemotherapy (Figure 2). ${ }^{1}$ Artemisins represent the key compounds in artemisinin-based combination therapy (ACT) that are presently the mainly used antimalarials..$^{5-8}$

The discovery of new antimalarial compounds is, therefore, urgent and natural products (NP) are sources of potentially lead compounds for modern medicine. ${ }^{3}$ Triterpenes are a class of NP with a wide distribution in plants being found in many medicinal plants and disclosing several biological effects such as anti-inflammatory, antitumor and antimalarial. ${ }^{9}$

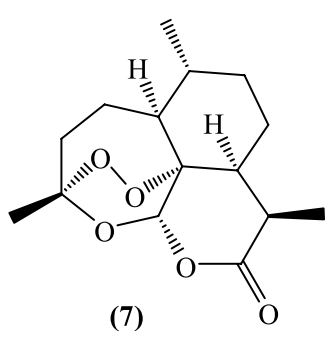

(7)

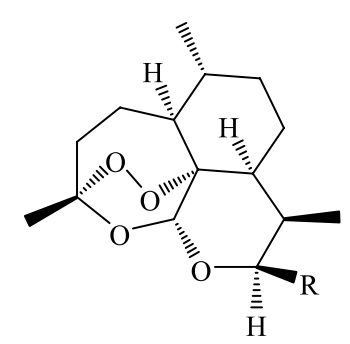

(8) $\mathrm{R}=\mathrm{OCO}\left(\mathrm{CH}_{2}\right)_{2} \mathrm{COOH}$ (9) $\mathrm{R}=\mathrm{OCH}_{3}$ (10) $\mathrm{R}=\mathrm{OCH}_{2} \mathrm{CH}_{3}$ (11) $\mathrm{R}=\mathrm{OH}$

Figure 2. Chemical structures of antimalarial sesquiterpene lactones: artemisinin (7), artesunate (8), artemether (9), arteether (10) and dihydroartemisinin (11).

Among the triterpenes, lupeol (12, Figure 3) is known to have a vast occurrence in diverse plant families, like Asteraceae. Lupeol and derivatives are also of

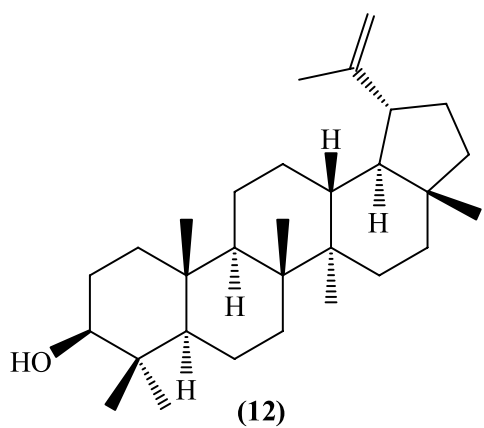

Figure 3. Chemical structure of lupeol (12).

pharmaceutical interest exhibiting a broad spectrum of biological activities. ${ }^{10}$

Its antimalarial activity was first reported in a bioguided fractionation of leaves hexane extract of Vernonia brasiliana (L.) Druce (Asteraceae) having disclosed a moderate effect in vitro against $P$. falciparum (BHZ 26/80) with 45\% parasite growth inhibition in the concentration of $25 \mu \mathrm{g} \mathrm{mL}^{-1}$. However, this triterpene was inactive in in vivo assays when $15 \mathrm{mg} \mathrm{kg}^{-1}$ were administered per os during four consecutive days to P. berghei infected mice. ${ }^{11}$ Since then, several lupeol derivatives have been evaluated against different P. falciparum strains with $50 \%$ maximal inhibitory concentration $\left(\mathrm{IC}_{50}\right)$ values in the range of 390 to $1.5 \mu \mathrm{g} \mathrm{mL}^{-1} .^{10}$ Thus, lupeol provides an interesting scaffold for structure diversification, what may result in the identification of more potent analogues. ${ }^{10}$ Indeed many chemical modifications of lupeol structure were done to improve the biological activity. Structural modification is 
a valid strategy aiming to improve the pharmacokinetic and pharmacological properties of a bioactive molecule. ${ }^{9}$

Several NP such as alkaloids, disclose relevant biological activities, ${ }^{12}$ as can be highlighted by the quinoline derivatives (quinine) of known antimalarial activity. ${ }^{4}$ In this context the introduction of nitrogenated moieties in non-alkaloids NP, such as 1,2,3-triazole rings is a good strategy to obtain more active compounds. ${ }^{13,14}$ In addition, the 1,2,3-triazole ring is exclusively synthetic and may be used for coupling between two or more molecules of interest aiming to improve their pharmacological and pharmacokinetic characteristics. ${ }^{15}$ An interesting example is the work developed by Guantai et al..$^{13}$ to obtain a new hybrid of chloroquinoline and chalcone by the synthesis of heterocyclic 1,2,3-triazoles with high antimalarial activity.

In the case of lupeol, the rational for the synthesis of a hybrid molecule with a 1,2,3-triazole ring was to create new possibilities of interactions with parasite targets through the nitrogens of the triazole ring. The synthesis of a heterocyclic $1,2,3$-triazole is usually carried out by a cycloaddition reaction between a terminal alkyne and an organic azide under catalyzis by copper(II). This reaction is called copper-catalyzed azide-alkyne cycloaddition (CuAAC) and is referred as a "click reaction". ${ }^{16}$ The CuAAC has been explored because of interesting characteristics such as mild reaction conditions, easy to execute, regioespecificity (only the 1,4-disubstituted isomer is obtained) and good yields. ${ }^{17-19}$

In this paper we report the isolation of lupeol from Parahancornia fasciculata, synthesis of five 1,2,3-triazole derivatives of this triterpene by click chemistry, their evaluation for in vitro activity against chloroquine resistant P. falciparum $\mathrm{W} 2$ strain and cytotoxicity against Hep G2 cells.

\section{Experimental}

\section{Materials and methods}

All solvents and chemicals were used as purchased without further purification. Melting points were determined using a MQAPF-307 melting point apparatus (Microquimica, Brazil) and are uncorrected. The progress of the reactions was monitored by thin layer chromatography (TLC) in silica gel plates. Column chromatography was performed over silica gel (60-230 mesh). Infrared spectra were recorded on a Spectra One PerkinElmer spectrophotometer, fitted with a Paragon ATR accessory. High-resolution mass spectrometry (HRMS) data were recorded on a Shimadzu liquid chromatography-mass spectrometry ion trap and time-of-flight (LCMS-IT-TOF) spectrometer using electron spray ionization (ESI) and waters ACQUITY tandem quadrupole detector (TQD). The ${ }^{1} \mathrm{H},{ }^{13} \mathrm{C}$ and DEPT 135 nuclear magnetic resonance (NMR) spectra were recorded on a Bruker Avance DPX 200 and DPX 400 spectrometer at 200 and $400 \mathrm{MHz}$ using $\mathrm{CDCl}_{3}$ as the solvent and tetramethylsylane (TMS) as the internal standard, unless otherwise stated. The NMR data are presented as follows: chemical shift, in ppm, multiplicity, number of protons, proton assignments and $J$ in Hz. Multiplicities are indicated by the following abbreviations: s (singlet), d (doublet), $\mathrm{dd}$ (double doublet), $\mathrm{t}$ (triplet), q (quartet), m (multiplet), qn (quintet) and brs (broad singlet).

\section{Plant material}

Barks of Parahancornia fasciculata were collected from one specimen identified by Prof M. R. Coelho-Ferreira, Universidade Federal Rural da Amazônia, in the experimental unity of Embrapa Amazônia Oriental, km 30 of road PA-150, Pará State, Brazil, in March 2011. A voucher specimen (ME202701) is deposited in the herbarium of Museum Paraense Emílio Goeldi, Belém-PA, Brazil. Plant material was kindly supplied by Prof Maria Fâni Dolabela, PPGCF, UFPA, Belém.

\section{Extraction and isolation of constituents}

Pulverized bark material ( $370 \mathrm{~g}$ ) was treated with $20 \mathrm{~mL}$ concentrated solution of $\mathrm{NH}_{4} \mathrm{OH}$ and percolated with $\mathrm{CH}_{2} \mathrm{Cl}_{2}$ at room temperature. The solvent was removed under pressure and the residue obtained (2.2 g) was chromatographed in a silica gel column. Fractions eluted with hexane and mixtures of hexane/dichloromethane were combined affording $800 \mathrm{mg}$ of a mixture of lupeol and 3-O-acyl lupeol esters. ${ }^{20}$

\section{Synthesis}

Hydrolysis of $3-O-a c y l$ lupeol esters mixture to obtain lupeol (12)

The mixture, previously obtained, containing lupeol and 3-O-acyl lupeol esters $(800 \mathrm{mg})$, was treated with $10 \% \mathrm{KOH}$ in $\mathrm{EtOH}(50 \mathrm{~mL})$, under reflux, for $3 \mathrm{~h}$ followed by extraction with $\mathrm{CH}_{2} \mathrm{Cl}_{2}$. The solvent was removed in under reduced pressure and the residue was submitted to chromatography in a silica gel column eluted with mixtures of hexane/dichloromethane giving $400 \mathrm{mg}$ of lupeol (12).

Lupeol propargyl ether [3ß-3'(prop-2'-yn-1'-iloxy)lup-20(29)ene] (13)

In a round bottom flask, kept under nitrogen, a solution of lupeol, (200 mg, $0.469 \mathrm{mmol})$ in dry tetrahydrofuran 
$(10 \mathrm{~mL})$ was added under stirring $\mathrm{NaH}(56 \mathrm{~g}, 2.34 \mathrm{mmol})$. After $30 \mathrm{~min}$, propargyl bromide ( $278 \mathrm{mg}, 2.34 \mathrm{mmol}$ ) was added to the reaction mixture that was kept under stirring at room temperature for $24 \mathrm{~h}$. Subsequently the mixture was extracted with ethyl acetate, followed by extraction with a solution of $20 \% \mathrm{NaOH}$ in water and brine. The crude reaction product, obtained after solvent removal, was purified by silica gel column chromatography eluted with a mixture of hexane/dichloromethane.

General procedure for the synthesis of lupeol 1,2,3-triazole derivatives (14a-e)

To a round bottom flask containing compound (13) (300 $\mathrm{mg}, 6.4 \mathrm{mmol})$, the organic azide $(6.4 \mathrm{mmol})$, in dichloromethane $(3 \mathrm{~mL})$ and water $(3 \mathrm{~mL})$, was added $\mathrm{CuSO}_{4} .5 \mathrm{H}_{2} \mathrm{O}(49.9 \mathrm{mg}, 0.20 \mathrm{mmol})$ and sodium ascorbate (39.6 $\mathrm{mg}, 0.20 \mathrm{mmol}$ ). The resulting mixture was vigorously stirred at room temperature for $24 \mathrm{~h}$. Subsequently the mixture was extract with dichloromethane, the organic layer was washed with a solution of ethylenediamine tetraacetic acid (EDTA, 50\% in $\mathrm{NH}_{4} \mathrm{OH}$ ), the organic solvent was removal and the residue was purified by silica gel column chromatography. The product was eluted with a mixture of hexane/dichloromethane leading to compound lupeol 1,2,3-triazole derivatives (Scheme 1). ${ }^{21,22}$

\section{In vitro sensitive drug assay}

Evaluation of the antiplasmodial activity of compounds 12, 13 and 14a-e was performed by in vitro assays against the chloroquine-resistant W2 strain of P. falciparum by determination of the lactate dehydrogenase assay $(p \mathrm{LDH}) .^{23,24}$

P. falciparum (W2 strain) was maintained in continuous culture, as describe by Trager and Jensen. ${ }^{24}$ Ring-stage parasites in sorbitol-synchronized blood cultures were added to 96 -well culture plates at $2 \%$ parasitemia and $1 \%$ hematocrit and then incubated with the test drugs that were diluted in complete medium, from $50 \mathrm{mg} \mathrm{mL}^{-1}$ stock solutions in dimethyl sulfoxide (DMSO), at final concentrations of $0.002 \%(\mathrm{v} / \mathrm{v})$ and stored at $37{ }^{\circ} \mathrm{C}$. After $48 \mathrm{~h}$ incubation period the plates were frozen $\left(-20{ }^{\circ} \mathrm{C}\right.$ for $24 \mathrm{~h}$ ) and thawed to start $p \mathrm{LDH}$ assay. ${ }^{23}$

The hemolyzed cultures were transferred to another 96-wells culture plate and add Malstat ${ }^{\circledR}$ and NBT/PES reagents. After $1 \mathrm{~h}$ of incubation at $37^{\circ} \mathrm{C}$ in the dark the absorbance was read at $540 \mathrm{~nm}$ in a spectrophotometer (Infinite ${ }^{\circledR} 200$ PRO, Tecan). The experiment was performed thrice each one in triplicate. The results were evaluated with the software Microcal Origin 8.5 for determination of the dose-response curves plotted with sigmoidal fit. The $\mathrm{IC}_{50}$ was determined by comparison with controls with standard drug and without drugs.

Cytotoxicity evaluation was carried out in human hepatome cell cultures (Hep G2). ${ }^{7}$ Cultures of Hep G2 cells were kept at $37{ }^{\circ} \mathrm{C}$ in RPMI medium supplemented with 5\% fetal calf serum (complete medium) in a 5\% $\mathrm{CO}_{2}$ environment. Cells from confluent monolayers were trypsinized, washed, counted, diluted in complete medium, distributed in 96-well microtiter plates $\left(4 \times 10^{5}\right.$ cells per well $)$, and then incubated for another $18 \mathrm{~h}$ at $37{ }^{\circ} \mathrm{C}$. The compounds to be tested (with or without the test drugs added to the cultures) were diluted in DMSO (final concentration of 0.02\%). After $24 \mathrm{~h}$ incubation at $37^{\circ} \mathrm{C}, 28 \mu \mathrm{L}$ of MTT solution $\left(2 \mathrm{mg} \mathrm{mL}^{-1}\right.$ in PBS) was added to each well. After $1.5 \mathrm{~h}$ of incubation at $37^{\circ} \mathrm{C}$, the supernatant was removed, and $130 \mu \mathrm{L}$ of DMSO was added to each well. The experiment was performed thrice each one in triplicate. The culture plates were read by a spectrophotometer with a $510 \mathrm{~nm}$. The minimum lethal dose that killed $50 \%$ of the cells $\left(\mathrm{CC}_{50}\right)$ was determined; each assay was performed three time. ${ }^{7}$ Aiming to evaluate the selectivity of the determined antimalarial activity of the compounds to $P$. falciparum $\mathrm{W} 2$, the selectivity index (SI) was calculated based on the rate between $\mathrm{CC}_{50}$ and $\mathrm{IC}_{50}$ for the in vitro activity against Hep G2 and P. falciparum, respectively. ${ }^{25}$

Values of lipophilicity $(\log \mathrm{P})$ and water solubility ( $\log \mathrm{S}$ ) for lupeol (12) and derivatives 13 and 14a-e were estimated by the Chemaxon's Calculator Plugins ${ }^{26}$ to check the water $/ n$-octanol solubility of the synthetized compounds in relation to lupeol since this is a factor that can influence in the biological tests.

\section{Results and Discussion}

\section{Chemistry}

A dichloromethane extract of Parahancornia fasciculata bark previously treated with $\mathrm{NH}_{4} \mathrm{OH}$, afforded a mixture of lupeol and 3-O-acyl lupeol esters with $0.22 \%$ yield..$^{27}$ This mixture was hydrolyzed to obtain lupeol (yield 50\%) that was characterized by NMR and IR spectroscopy besides comparison with authentic sample. ${ }^{28,29}$ Lupeol was used as the starting material for all chemical reactions presented in this paper. A total of 6 new lupeol derivatives, whose structures are depicted in Scheme 1, were synthesized.

The propargyl ether of lupeol [3ß-3' (prop-2'-yn-1'-iloxy) lup-20(29)-ene] (13), necessary for the click reaction with organic azides, was synthesized by a nucleophilic substitution reaction between propargyl bromide and lupeol, in the presence of $\mathrm{NaH}$, in dry tetrahydrofuran (THF), with $54 \%$ yield. ${ }^{22}$ Its IR spectrum showed characteristic bands in 


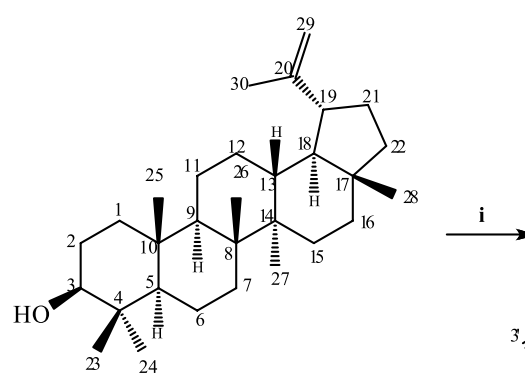

12<smiles>CCc1[c]cnc2cc(Cl)ccc12</smiles>

$14 \mathrm{a}(65 \%)$

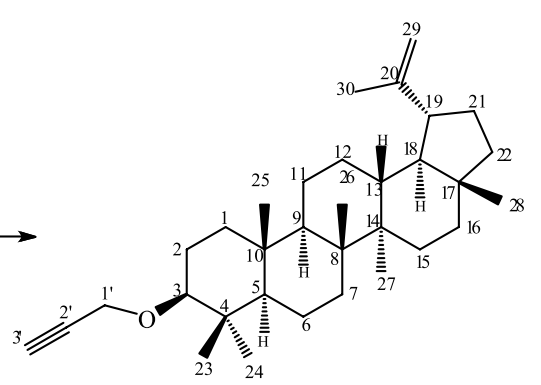

13

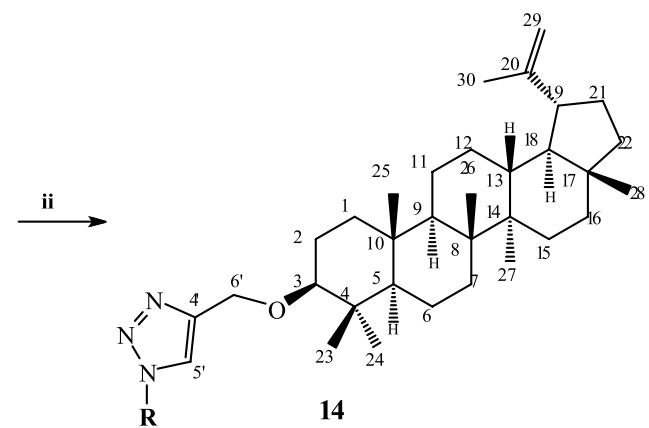<smiles>CCc1ccccc1</smiles>

$14 d(45 \%)$

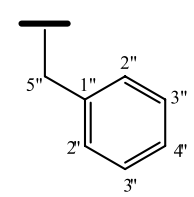

$14 \mathrm{e}(70 \%)$

Scheme 1. Synthesis of compounds 13 and 14a-14e from lupeol (12). Reagents and conditions: (i) $\mathrm{C}_{3} \mathrm{H}_{3} \mathrm{Br} / \mathrm{NaH} / \mathrm{THF}$, room temperature (r.t.), 24 h; (ii) organic azide, $\mathrm{CuSO}_{4} .5 \mathrm{H}_{2} \mathrm{O}(20 \mathrm{~mol} \%), \mathrm{CH}_{2} \mathrm{Cl}_{2} / \mathrm{H}_{2} \mathrm{O}\left(50 \%\right.$ v/v), r.t., 24 h. ${ }^{22}$

3253 and $2112 \mathrm{~cm}^{-1}$ relative to stretch of $\mathrm{C}-\mathrm{H}$ and $\mathrm{C}-\mathrm{C}$ of terminal alkyne bonds, respectively, besides an intense band at $1071 \mathrm{~cm}^{-1}$ relative to the ether $\mathrm{C}-\mathrm{O}$ bond..$^{22}$

The ${ }^{1} \mathrm{H}$ NMR spectrum of $\mathbf{1 3}$ showed three signals for the propargyl moiety: at $\delta 4.21$ and 4.13 ppm relative to the two olefin hydrogens $\mathrm{H}-1$ ' and at 2.35 ppm relative to $\mathrm{H}-3$ '. These signals confirm the insertion of a propargyl group in the lupeol structure..$^{22}$ The spectrum of $\mathbf{1 3}$ displayed common signals with lupeol, ${ }^{28,29}$ which appeared at $\delta 4.68$ and $4.56 \mathrm{ppm}$ related to the two olefin hydrogens $\mathrm{H}-29$, at $3.0 \mathrm{ppm}$ relative to the oxymethine $\mathrm{H}-3$ (dd, $1 \mathrm{H}, \mathrm{H}-3, J 4.0$, $11.60 \mathrm{~Hz}, \mathrm{H} 3 / \mathrm{H} 2$ ) and the seven singlet signals assigned to the tertiary methyl groups at $\delta 0.76,0.78,0.83,0.94,0.97$, 1.03 and 1.65 ppm relative to: $\mathrm{H}-23, \mathrm{H}-24, \mathrm{H}-25, \mathrm{H}-26$, $\mathrm{H}-27, \mathrm{H}-28$ and $\mathrm{H}-30$, respectively. The ${ }^{13} \mathrm{C}$ NMR spectrum of $\mathbf{1 3}$ showed three signals for the propargyl moiety at $\delta 63$, 43 and 48 ppm relative of C-1', C-2' and C-3', respectively. These spectra displayed common signals to lupeol ${ }^{28,29}$ at $\delta 151$ (C-20), 109.54 (C-29) and at 86 ppm (C-3). The mass spectrum of $\mathbf{1 3}$ registered by LC-MS in the positive mode showed the molecular ion peak at $m / z, 465.4061[\mathrm{M}+\mathrm{H}]$, which loses a $\mathrm{C}_{3} \mathrm{H}_{4} \mathrm{O}$ neutral molecule to give the base peak at $409.3805 \mathrm{u}$.

The CuAAC, often referred to as "click reaction", occurred between the terminal alkyne of the lupeol propargyl ether (13) and known organic azides ${ }^{17-19,21}$ that were previously synthesized..$^{22} \mathrm{CuAAc}$ is known for its high efficiency without need for special reaction conditions, such as high temperature and/or high pressure, and is regioselective giving only the 1,4-disubstituted isomer. ${ }^{17-19}$ The conditions of the click reactions used to prepare 14a-e (24 hours of reaction, dichloromethane and water as solvents) were similar to those previously described. ${ }^{21,22}$ The products were obtained with yields ranging from 45 to $75 \%$.

The ${ }^{1} \mathrm{H}$ NMR spectra of the click reaction products 14a-e (Scheme 1) showed signals at $\delta$ 7-8 ppm relative to $\mathrm{H}-5$ ', the only hydrogen of the triazole ring, and at $\delta$ 4.5-4.8 ppm relative to H-6'. ${ }^{22}$ Signals related to the lupeol moiety remained practically unchanged: $\delta 4.5 \mathrm{ppm}$ for $\mathrm{H}-29 ; 2.8-3.0 \mathrm{ppm}$ relative to $\mathrm{H}-3$ and the signals of seven methyl groups in the region of $\delta$ 0.5-2.0 ppm.

The ${ }^{13} \mathrm{C}$ NMR spectra displayed three signals at $\delta 63$ (C-6'), 120-124 (C-5') and 137-154 ppm (C-4') relative to the triazole-ring carbons. The other signals related to the lupeol moiety remained at $\delta 129(\mathrm{C}-29)$ and 86-87 ppm (C-3).

The mass spectra of the lupeol triazole derivatives showed the expected molecular ion peaks at $[\mathrm{M}+\mathrm{H}]$, a fragment ion at $[\mathrm{M}-28 \mathrm{u}]$ related to a $\mathrm{N}_{2}$ lost and a peak at $409 \mathrm{u}$ for the fragment ion related to the loss of groups bonded to the oxygen at $\mathrm{C}-3 .{ }^{22}$

\section{Biological evaluation}

The antiplasmodial activity of lupeol (12), lupeol propargyl ether (13) and the 1,2,3-triazole lupeol derivatives (14a-e) was assessed by in vitro tests against the chloroquine-resistant $\mathrm{W} 2$ clone of $P$. falciparum according to the $p \mathrm{LDH}$ methodology. ${ }^{23}$ Results are shown in Table 1. Compound $\mathbf{1 3}$ disclosed a moderate antiplasmodial activity with $\mathrm{IC}_{50}$ of $62.4 \mu \mathrm{mol} \mathrm{L} \mathrm{L}^{-1}$. It was more potent than lupeol that disclosed a weak effect $\left(\mathrm{IC}_{50}=117.4 \mu \mathrm{mol} \mathrm{L}{ }^{-1}\right)$. It is interesting to point out that this is the first report on the $\mathrm{IC}_{50}$ 
Table 1. Concentrations that induce 50\% inhibition of cell growth ( $\left.\mathrm{IC}_{50}\right)$ of Plasmodium falciparum chloroquine-resistant (W2), concentration that kills $50 \%$ of Hep G2 cells $\left(\mathrm{CC}_{50}\right)$, selectivity index (SI), estimated values of lipophilicity $(\log \mathrm{P})$ and water solubility $(\log \mathrm{S})$ for lupeol $(\mathbf{1 2})$ and derivatives $\mathbf{1 3}$ and $\mathbf{1 4 a - e}$

\begin{tabular}{|c|c|c|c|c|c|}
\hline Compound & $\mathrm{IC}_{50}{ }^{\mathrm{a}} /\left(\mu \mathrm{mol} \mathrm{L}{ }^{-1}\right)$ & $\mathrm{CC}_{50}{ }^{\mathrm{b}} /\left(\mu \mathrm{mol} \mathrm{L}{ }^{-1}\right)$ & $\mathrm{SI}^{\mathrm{c}}$ & $\log \mathrm{P}^{\mathrm{d}}$ & $\log \mathrm{S}^{\mathrm{d}}$ \\
\hline 12 & $>117.00$ & 710.00 & $>6.07$ & 7.45 & -8.94 \\
\hline 13 & $62.40 \pm 1.92$ & 112.00 & $>1.80$ & 8.32 & -10.00 \\
\hline $14 a$ & $>200.00$ & $>1496.00$ & $>7.48$ & 10.36 & -18.18 \\
\hline $14 b$ & $>200.00$ & $>1712.00$ & $>8.56$ & 8.38 & -9.29 \\
\hline $14 c$ & $>200.00$ & $>1672.00$ & $>8.36$ & 8.53 & -9.28 \\
\hline $14 d$ & $>200.00$ & 635.00 & $>3.17$ & 9.60 & -10.43 \\
\hline $14 e$ & $>200.00$ & $>1675.00$ & $>8.37$ & 9.67 & -10.29 \\
\hline $\mathrm{CQ}^{\mathrm{e}}$ & 0.50 & 685.00 & 1370.00 & $3.93(4.63)^{\mathrm{d}}$ & -3.70 \\
\hline
\end{tabular}

${ }^{\mathrm{a}} \mathrm{IC}_{50}$ : concentration that kills $50 \%$ of $P$. falciparum, determined by the $p \mathrm{LDH}$ method; ${ }^{\mathrm{b}} \mathrm{CC}_{50}$ : concentration that kills $50 \%$ of $\mathrm{Hep} \mathrm{G} 2$ cells $24 \mathrm{~h}$ after incubation with the compounds, determined by the MTT method; 'SI (selectivity index): $\mathrm{CC}_{50} / \mathrm{IC}_{50}$; ${ }^{\mathrm{d} e s t i m a t e d} \log \mathrm{P}$ and $\log \mathrm{S}$ by Chemaxon's Calculator Plugins; $;{ }^{26} \mathrm{CQ}$ : chloroquine.

determination for lupeol against W2 strain, a chloroquine resistant $P$. falciparum. Alves et al. ${ }^{11}$ showed that lupeol caused $45 \%$ of growth inhibition of $P$. falciparum (BHZ 26/86) at the concentration of $60 \mu \mathrm{M}$. However, the $\mathrm{IC}_{50}$ was not determined. A review reports $\mathrm{IC}_{50}$ values for several P. falciparum strains from $1.5 \mu \mathrm{g} \mathrm{mL} \mathrm{mL}^{-1}(3.5 \mu \mathrm{M}$ in K1) to $398 \mu \mathrm{g} \mathrm{mL}{ }^{-1}$ (932.7 $\mu \mathrm{M}$ in 3D7). ${ }^{10}$

The 1,2,3-triazole derivatives 14a-e were less active than lupeol $\left(\mathrm{IC}_{50}>200 \mu \mathrm{mol} \mathrm{L}{ }^{-1}\right)$. These results might be explained by an increase in molecular mass of the triazole derivatives and, therefore, an increase of their lipophilicity. It must be emphasized that, it was expected an improvement of the antiplasmodial activity because of the three heterocyclic nitrogens in the 1,2,3-triazole derivatives, that would increase the interaction with parasite. However, an opposite effect was observed and a possible explanation might be the increase of their lipophilicity, as can be inferred from the calculated values of $\log \mathrm{P}$ and $\log \mathrm{S}$ (Table 1) and, consequently, the decrease of their biological activity.

The high lipophilicity (Table 1 ) of compounds $\mathbf{1 2}, \mathbf{1 3}$ and 14a-e might affect their solubility during the biological tests and, consequently, the antiplasmodial activity. It has been demonstrated that the antimalarial mode of action of lupeol and other triterpenes seems to be related to alterations in the parasite membrane rather than to a targeted toxic effect on the parasite organelles or metabolic pathways. ${ }^{30}$ Therefore, the propargyl ether of lupeol (13) has possibly enhanced the alterations of parasite membranes or might have another site of action into $P$. falciparum. ${ }^{30}$ Interestingly, Olagnier et $a l .{ }^{31}$ have previously observed that introduction of an alkyne moiety into a monoterpene skeleton increased the antimalarial activity.
The cytotoxicity of compounds was evaluated in human hepatome cell cultures, Hep G2 cells, by the MTT method ${ }^{7}$ and the results are shown in Table 1. The new compounds disclosed lower cytotoxicity than lupeol and chloroquine (reference drug), except compounds $\mathbf{1 3}$ and 14d. The calculated selectivity index (SI) of each compound to parasite was $<10$. It should be noticed that the lowest SI was for the propargyl ether (13) that was more active than lupeol but disclosed higher cytotoxicity to Hep G2 cells.

\section{Conclusions}

A total of six new compounds were synthetized (13, 14a-e) in good yields. The propargyl ether of lupeol (13) was the only one out of the six new derivatives of lupeol to disclosing a moderate increase of the antiplasmodial activity, although it was also more cytotoxic to Hep G2 cells. Therefore, it might be pointed out as potential cytotoxic agent rather than antimalarial. The 1,2,3-triazole derivatives were all less potent than lupeol against the chloroquine-resistant $P$. falciparum. The decrease of their antiplasmodial activity in relation to lupeol might be related to their high lipophilicity, and, therefore, low solubility of compounds in the conditions of the in vitro tests. The 1,2,3-triazole derivatives have shown lower cytotoxicity than lupeol, except compound 14d that might be of interest for other potential pharmaceutical applications. On the other hand, the increased antiplasmodial activity of the propargyl ether (13) stimulates further structural modifications of the lupeol structure aiming to enhance the antimalarial activity. 


\section{Supplementary Information}

A list of all spectroscopic data is available free of charge at http://jbcs.sbq.org.br as a PDF file.

\section{Acknowledgments}

To Conselho Nacional de Desenvolvimento Científico e Tecnológico/CNPq/PRONEX Rede Malária (Process No. 555655/2009-1) and Fundação de Amparo à Pesquisa do Estado de Minas Gerais/FAPEMIG (Process No. CDS APQ 01129-10) for financial support. Fellowships to G. R. P. (PDJ/FAPEMIG), G. C. B. (PDJ/CNPq), H. A. O. J. (BIC/CNPq), R. C. P. (D/CNPq) and M. F. A. N. (DTI2/ FAPEMIG) are fully acknowledged.

\section{References}

1. Vale, N.; Moreira, R.; Gomes, P.; Quimica 2006, 99, 1.

2. http://apps.who.int/iris/bitstream/10665/200018/1/9789241565158_ eng.pdf?ua=1 accessed in January 2017.

3. Oliveira, A. B.; Dolabela, M. F.; Braga, F. C.; Jácome, R. L. R. P.; Varotti, F. P.; Póvoa, M. M.; An. Acad. Bras. Cienc. 2009, 81,715 .

4. França, T. C. C.; Santos, M. G.; Villar, J. D. F.; Quim. Nova 2008, 31, 1271.

5. Krogstad, D. J.; Herwaldt, B. L.; Schlesinger, P. H.; Antimicrob. Agents Chemother. 1988, 32, 957.

6. Wang, J.; Cao, W.; Shan, C.; Zhang, M.; Li, G.; Ding, D.; Shi, Y.; Wu, B.; Acta Trop. 2004, 89, 375.

7. Varotti, F. P.; Botelho, A. C. C.; Andrade, A. A.; Paula, R. C.; Fagundes, E. M. S.; Valverde, A.; Mayer, L. M. U.; Mendonça, J. S.; Souza, M. V. N.; Boechat, N.; Krettli, A. U.; Antimicrob. Agents Chemother. 2008, 52, 3868.

8. Prachayasittikul, S.; Saraban, P.; Cherdtrakulkiat, R.; Ruchirawat, S.; Prachayasittikul, V.; EXCLI J. 2010, 9, 1.

9. Srinivasan, T.; Srivastava, G. K.; Pathak, A.; Batra, S.; Raj, K.; Singh, K.; Puri, S. K.; Kundu, B.; Bioorg. Med. Chem. Lett. 2002, 12, 2803.

10. Gallo, M. B. C.; Sarachine, M. J.; Int. J. Biomed. Pharmaceut. Sci. 2010, 1.

11. Alves, T. M.; Nagem, T. J.; Carvalho, L. H.; Krettli, A. U.; Zani, C. L.; Planta Med. 1997, 63, 554.

12. Pholshettiwar, V.; Varma, R. S.; Pure Appl. Chem. 2008, 80, 777.
13. Guantai, E. M.; Ncokazi, K.; Egan, T. J.; Gut, J.; Rosenthal, P. J.; Smith, P. J.; Chibale, K.; Bioorg. Med. Chem. 2010, 18, 8243.

14. Pagliai, F.; Pirali, T.; del Grosso, E.; di Brisco, R.; Tron, G. C.; Sorba, G.; Genazzani, A. A.; J. Med. Chem. 2006, 49, 467.

15. Meldal, M.; Tornøe, C. W.; Chem. Rev. 2008, 108, 2952.

16. Lee, B.; Park, S. R.; Jeon, H. B.; Kim, K. S.; Tetrahedron Lett. 2006, 47, 5105.

17. Kolb, H. C.; Finn, M. G.; Sharpless, K. B.; Angew. Chem., Int. Ed. 2001, 40, 2004.

18. Hein, J. E.; Tripp, J. C.; Krasnova, L. B.; Sharpless, K. B.; Fokin, V. V.; Angew. Chem., Int. Ed. 2009, 48, 8018.

19. Freitas, L. B. O.; Ruela, F. A.; Pereira, G. R.; Alves, R. B.; Freitas, R. P.; Quim. Nova 2011, 34, 1791.

20. Carvalho, M. G.; Velloso, C. R. X.; Braz-Filho, R.; Costa, W. F.; J. Braz. Chem. Soc. 2001, 12, 556.

21. Pereira, G. R.; Brandão, G. C.; Arantes, L. M.; Oliveira, H. A.; Paula, R.; Nascimento, M. F. A.; Santos, F. M.; Rocha, R. K.; Lopes, J. C. D.; Oliveira, A. B.; Eur. J. Med. Chem. 2014, 73, 295.

22. Santos, J. O.; Pereira, G. R.; Brandão, G. C.; Borgati, T. F.; Arantes, L. M.; de Paula, R. C.; Soares, L. F.; do Nascimento, M. F. A.; Taranto, A. G.; Varotti, F. P.; de Oliveira, A. B.; J. Braz. Chem. Soc. 2015, 27, 551.

23. Makler, M. T.; Piper, R. C.; Milhous, W. K.; Parasitol. Today 1998, 14,1 .

24. Trager, W.; Jensen, J. B.; Science 1976, 80, 673.

25. Bézivin, C.; Tomasi, S.; Lohézic-Le Dévéhat, F.; Boustie, J.; Phytomedicine 2003, 10, 499.

26. https://www.chemaxon.com/products/calculator-plugins/, accessed in January 2017.

27. Sobrinho, D. C.; Hauptli, M. B.; Appolinário, E. V.; Kollenz, C. L. M.; Carvalho, M. G.; Braz-Filho, R.; J. Braz. Chem. Soc. 1991, 2, 15.

28. Sholichin, M.; Kazuo, Y.; Kasai, R.; Tanaka, O.; Chem. Pharm. Bull. 1980, 28, 1006.

29. Prakash, C. V. S.; Prakash, I.; Res. J. Pharm. Sci. 2012, 1, 23.

30. Ziegler, H.; Staals $\varnothing$, T.; Jaroszewski, J.; Planta Med. 2006, 72, 640.

31. Olagnier, D.; Costes, P.; Berry, A.; Linas, M.; Urrutigoity, M.; Dechy-Cabaret, O.; Vical, F. B.; Bioorg. Med. Chem. Lett. 2007, 17,6075 .

Submitted: November 12, 2016

Published online: February 3, 2017 